\title{
Nugent Scores of Pregnant Women in a Tertiary Institution in Nigeria
}

\author{
Grace Ajani $^{{ }^{*}}$, Oyin Oduyebo ${ }^{2}$, Muyideen Haruna ${ }^{1}$, Charles Elikwu ${ }^{2}$ \\ ${ }^{1}$ Babcock University, Ilishan-Remo, Nigeria \\ ${ }^{2}$ College of Medicine, University of Lagos, Lagos, Nigeria \\ Email: ${ }^{*}$ caacfa@yahoo.com
}

Received July 11, 2012; revised August 30, 2012; accepted September 14, 2012

\begin{abstract}
Background: Bacterial Vaginosis (BV) is an imbalance of the vaginal normal flora, and it is asymptomatic in most women. Therefore, one of the major ways of diagnosing BV is demonstration of an abnormal flora in the vagina. This can be achieved through various methods including Nugent score. In view of the association of BV with obstetric/gynaecological complications and high rate of HIV transmission, it is desirable to know the prevalence of BV in pregnant women. Knowledge of risk factors will also help to design preventive measures. Methodology: A prospective study was performed to determine the prevalence of BV among pregnant women. High vaginal swabs (HVS) were collected and smears made were Gram stained and scored by the Nugent method. A predesigned questionnaire was also used to obtain information on possible risk factors. Associations between categorical variables were assessed using chi square test and fisher's exact test as appropriate. Result: Three hundred married women aged between 18 and 45 years were studied. The prevalence of BV was $64.3 \%, 25 \%$ had intermediate and $10.7 \%$ had negative Nugent scores. BV rates were high across all age groups, educational background, ethnicity, parity, HIV status, and occupation. The occurrence of BV was higher $(75.5 \%)$ among gestational age group $\leq 30$ weeks $(p<0.05)$, in women who had sex more than twice within a week $(p<0.05)$ and in women who engaged in unskilled labour $(p<0.05)$. Conclusion: Bacterial vaginosis is a very common condition among the studied population. This high prevalence may necessitate routine screening and treatment during antenatal care in preventing the associated adverse effects of BV during pregnancy and childbirth.
\end{abstract}

Keywords: Bacterial Vaginosis; Preterm Labour; Pelvic Inflammatory Disease; Lactobacillus; Garneralla vaginalis; Mobiluncus spp

\section{Introduction}

Soon after birth, aerobic lactobacilli appear in the vagina and persist as long as the $\mathrm{pH}$ remains acidic (usually for several weeks). When the $\mathrm{pH}$ becomes neutral (remaining so till puberty), a mixed flora of cocci and bacilli is present. At puberty, aerobic and anaerobic lactobacilli reappears in large numbers and contributes to the maintenance of acidic $\mathrm{pH}$ through the production of acid from carbohydrate particularly glycogen [1]. Lactobacilli produce lactic acid, which maintains the normal vagina flora (pH 3.8 - 4.5) and inhibits the adherence of other bacteria to the epithelial cells of the vagina.

Bacterial Vaginosis (BV) is an infection of the vagina associated with an imbalance in the normal flora [2]. It is characterized by an increased vaginal $\mathrm{pH}$ and replacement of vaginal lactobacilli (particularly those that produce hydrogen peroxide $\left(\mathrm{H}_{2} \mathrm{O}_{2}\right)$ with Gardnerella vaginalis, Mycoplasma hominis and anaerobic Gram negative

${ }^{*}$ Corresponding author. bacteria such as Peptostreptococcus, Prevotella spp and Mobiluncus spp [3]. Associated with these vagina flora change, is a rise in the vagina $\mathrm{pH}$, increased level of production of proteolytic enzymes, organic acids and volatile amines [4].

It has been estimated that about 5 to 30 percent of women in the reproductive age group have BV and are asymptomatic. The most common symptom of BV is an abnormal homogeneous off-white vaginal discharge (especially after sex) with an unpleasant smell. This malodorous discharge coats the walls of the vagina and is usually without irritation, pain or erythema.

Prevalence of BV varies between $8 \%$ to $75 \%$ [5]. In the general population of women, prevalence is found to be $10 \%$ in Hispanics, $6 \%$ in Asians, $23 \%$ in AfricanAmerican, 30\% in Indonisia, 25\% in Canada [6], 15\% in rural Brasil [7] and $14.2 \%$ amongst a population of Nigerian women [8]. $13 \%$ among adolescent girls, $16 \%$ in pregnant white women [9], 9\% in non-pregnant white.

Detection of every case is very important especially in 
pregnant women not only because it increases the risk of Sexually Transmitted Infections (STIs) but also because it leads to adverse reproductive outcomes and complication in pregnancy [10].

Some serious concerns from BV includes increased susceptibility to HIV infection [11], post operative infection following gynaecological procedures such as a hysterectomy or an abortion [11], obstetric complications such as: preterm labour and preterm delivery, premature rupture of the membranes [12], chorioamnionitis, postpartum endometritis, postpartum sepsis, spontaneous miscarriage, and pelvic inflammatory disease (PID) which can lead to infertility and fallopian tube damage with an increased risk for ectopic pregnancy [11].

The usual medical regimen for treatment is the antibiotic metronidazole (400 $\mathrm{mg}$ or $500 \mathrm{mg}$ twice a day, once every 12 hours) for 7 days or $250 \mathrm{mg}$ three times a day for 7 days [10]. A Cochrane review of 2009 did not find probiotics useful in the treatment of BV [13] while another concluded they were effective when combined with antibiotics [14]. Also, supplements of the probiotic lactobacillus, alongside the antibiotic metronidazole, appeared to increase metronidazole's effectiveness [10].

The present study was undertaken to determine the prevalence of bacterial vaginosis by Nugent scoring among pregnant women of the Lagos University Teaching Hospital (LUTH), and possible risk factors.

\section{Methodology}

This was a hospital based prospective study conducted between December and July 2011, at the Lagos University Teaching Hospital, Lagos (LUTH), a tertiary care facility located at Lagos, South West Nigeria. LUTH provides healthcare services for the entire Lagos area but majority of patients are from Mushin, Oshodi-Isolo and Surulere local government areas of the state.

Pregnant women aged between 18 - 45 years with a gestational age of $\geq 28$ weeks, attending the antenatal outpatient department of LUTH were studied for prevalence of BV. After giving informed consent, a detailed obstetric history was taken especially to identify the risk possible factors for BV. Demographic data were also collected from the women with a simple structured questionnaire. Those with history of intake of antibiotics during the previous two weeks were excluded from the study, which was approved by the Health Research and Ethics committees of LUTH.

High vaginal swabs was collected from eligible women (Gestational age 28 weeks and above) and transported on ice less than two hours of collection to the Microbiology laboratory in the Department of Medical Microbiology and Parasitology, College of Medicine of the University of Lagos.

\subsection{Nugent Score}

Using Nugent criteria [15], the slides of direct Gram stain were carefully examined for morphotypes present in the vaginal specimens.

\subsection{Principle}

Nugent scoring system quantitates the number of large Gram positive rods (Lactobacillus morphotypes), small Gram negative to Gramvariable rods (Gadnerella vaginalis and Bacteroides species morphotypes) and curved Gram-variable rods (Mobiluncus species morphotypes) viewed on Gram stained smears to obtain a point summation of $0-10$ based on the sum of the scores for each bacterial morphotypes listed above

\subsection{Procedure}

The swabs of vaginal secretions obtained from the upper vagina were rolled over a clean, labelled slide to create a thin, evenly distributed smear of the material. The slides were allowed to air dry. Each dry smear was then heat fixed and Gram stained as previously described [16]. Five to 10 oil immersion fields was examined for the presence of Lactobacillus, Gadnerella vaginalis/Bacteroides and Mobiluncus morphotypes. Nugent score (a number between 0 and 10) is then calculated by summing assigned points. A score of $0-3$ is considered negative for bacteria vaginosis. A score of $4-6$ is considered intermediate. A score of $7-10$ is considered positive for bacteria vaginosis.

\subsection{Statistical Analysis}

Data were entered and analyzed using Epi-Info software, version 3.5.1 August 2008. Frequency tables and crosstables were used to present the data. Associations between categorical variables were assessed using chi square test and fisher's exact test as appropriate. The significance level was set at $\mathrm{p}<0.05$.

\section{Results}

Between December 2010 to July 2011, 300 married pregnant women attending LUTH antenatal clinic were studied. All of which were physically healthy and only came for their routine antenatal clinic except a few who are HIV positive but still looking very healthy. All the women were in their reproductive age, majority have at least a tertiary education. Though 300 women who participated were assessed by Nugent score only 295 had complete data and were available for statistical analysis.

The overall and subpopulation of $\mathrm{BV}$ is presented in Table 1. The prevalence of BV in the general population of the women was high, 203 of the women $(67.7 \%)$ were positive for BV, $67(22.3 \%)$ were intermediate and 30 
Table 1. Prevalence of bacterial vaginosis among pregnant women by sociodemographic characteristics and reproductive history.

\begin{tabular}{|c|c|c|c|}
\hline & Positive & Negative/Intermediate & \multirow{2}{*}{$\mathbf{p}$} \\
\hline & n (\%) & n (\%) & \\
\hline All Women & 67.7 & 32.3 & \\
\hline \multicolumn{4}{|l|}{ Age } \\
\hline$<20$ & $3(60)$ & $2(40)$ & \\
\hline$>20-35$ & $168(68.8)$ & $76(31.1)$ & \\
\hline$>35$ & $27(58.7)$ & $19(41.3)$ & 0.38 \\
\hline \multicolumn{4}{|l|}{ Education } \\
\hline Nil & $1(50)$ & $1(50)$ & \\
\hline P.E & $3(60)$ & $2(40)$ & \\
\hline S.E & $47(73.4)$ & $17(26.6)$ & \\
\hline T.E & $147(65.6)$ & $77(34.4)$ & 0.62 \\
\hline \multicolumn{4}{|l|}{ Occupation } \\
\hline Professional & $32(50)$ & $32(50)$ & \\
\hline Skilled & $40(74.1)$ & $14(25.9)$ & \\
\hline Unskilled & $68(73.9)$ & $24(26.1)$ & \\
\hline None & $58(68.2)$ & $27(31.8)$ & 0.008 \\
\hline \multicolumn{4}{|c|}{ Coital Frequency } \\
\hline$<2$ & $93(60.8)$ & $60(39.2)$ & \\
\hline$\geq 2$ & $105(73.9)$ & $37(26.1)$ & 0.02 \\
\hline \multicolumn{4}{|l|}{ Parity } \\
\hline$\leq 2$ & $117(61.6)$ & $73(38.4)$ & \\
\hline $2-4$ & $68(78.2)$ & $19(21.8)$ & \\
\hline$>4$ & $13(72.8)$ & $5(27.8)$ & 0.02 \\
\hline \multicolumn{4}{|l|}{ Ethnicity } \\
\hline Hausa & $1(33.3)$ & $2(66.7)$ & \\
\hline Igbo & $100(73.5)$ & $36(26.5)$ & \\
\hline Yoruba & $82(63.1)$ & $48(36.9)$ & \\
\hline Others & $15(57.7)$ & $11(42.3)$ & 0.10 \\
\hline \multicolumn{4}{|l|}{ HIV status } \\
\hline HIV+ & $13(86.7)$ & $2(13.3)$ & \\
\hline HIV- & $185(66.1)$ & $95(33.9)$ & 0.15 \\
\hline \multicolumn{4}{|l|}{ Gestational Age } \\
\hline$\leq 30$ & $37(75.5)$ & $12(24.5)$ & \\
\hline$>30-35$ & 70 (78.7) & $19(21.3)$ & \\
\hline$>35$ & $91(57.9)$ & $66(42.1)$ & 0.002 \\
\hline
\end{tabular}

Key: P.E: primary education; S.E: secondary education; T.E: tertiary education.
$(10.0 \%)$ were negative. BV rates were high across all age groups, educational background, ethnicity, occupation, parity and women who have sex at least twice per week. It was also observed that prevalence was higher, $86.7 \%$ (13 of 15), among HIV positive patient than in HIV negative patients $62.5 \%$ (Table 1) but with no statisticcally significant difference $(p=0.1)$. There was a significant correlation between $\mathrm{BV}$ and parity $(\mathrm{p}<0.05$; Table 2), GA ( $p<0.05$; Table 3), unskilled labour ( $<$ 0.05; Table 4) and frequency of sexual intercourse of more than twice per week ( $p<0.05$; Tables 5 and $\mathbf{6}$ ). On the other hand, no significant correlation was found between BV and age, education and ethnicity.

\section{Discussion}

The prevalence rate of BV of $63.7 \%$ was high in this study and this is consistent with previous studies in pregnant women. BV has been found to be common in black women. In county health center in Michigan, prevalence rates of $42 \%$ were documented [17] and 52\% also in the National Health and Nutrition Examination Survey [18] while in non pregnant black women, prevalence rate was $28 \%$ [19]. The prevalence of BV in pregnant women among white ranged from $12 \%$ to $21 \%$ [20].

The higher prevalence rate of $\mathrm{BV}$ in pregnant women compared with non pregnant women may be due to the fact that pregnant women are known to be immunosuppressed and this implies that such pregnant women may be more prone to obstetric infection. "Reference [21] showed that there was a significant trend of increased risk of HIV with increasing severity of vaginal disturbances among pregnant women". However, the high prevalence of BV in HIV positive patients observed in this study is not statistically significant $(p=0.1)$

Although a previous study found that BV prevalence increased with age [18], the age related increase in this study was not significant. This may be a result of disproportionately higher percentage of younger women (age 20 - 35) in the pregnant population. Previous studies suggested that $\mathrm{BV}$ is more prevalent in women who are sexually active. This can be further understood by this study that showed the highest prevalence in women who had sex at the minimum of twice in a week. Looking at the trend in Table 6, the occurrence of BV is low in women who have sex once a week and the prevalence increased with increasing coital frequency per week. Semen is alkaline and neutralizes the acidic $\mathrm{pH}$ of the vagina which results in an imbalance of the flora and this may explain the increase in the prevalence of women who had sex more than once in a week $(73.9 \%)$ as compared to women who had sex only once (60.8) in a week. The prevalence of BV decreases as gestational age increases $(75.5 \%$ among women who are $<30$ weeks and $57.9 \%$ in women $>35$ weeks). This is statistically sig- 
Table 2. Prevalence of BV in relation to parity number of pregnancy.

\begin{tabular}{cccc}
\hline Parity No of pregnancies & No of women with confirmed BV (\%) & No of women negative \& intermediate (\%) & Total no of women studied (\%) \\
\hline$\leq 2$ & $117(61.6)$ & $73(38.4)$ & 190 \\
$>2-4$ & $68(78.2)$ & $19(21.8)$ & 87 \\
$>4$ & $13(72.2)$ & $5(27.8)$ & 18 \\
& $198(63.73)$ & $97(36.27)$ & $295(100)$ \\
\hline
\end{tabular}

$X^{2}=7.66 ; p$ value $=0.02 ; \mathrm{df}=2$.

Table 3. Prevalence of BV in relation to gestational age of women.

\begin{tabular}{cccc}
\hline Gestational age & No of women with confirmed BV (\%) & No of women negative \& intermediate (\%) & Total no of women studied (\%) \\
\hline$\leq 30$ & $37(75.5)$ & $12(24.5)$ & 49 \\
$>30-35$ & $70(78.7)$ & $19(21.3)$ & 89 \\
$>35$ & $91(57.9)$ & $66(42.0)$ & 157 \\
& $198(67.7)$ & $97(32.3)$ & $295(100)$ \\
\hline
\end{tabular}

$\mathrm{X}^{2}=12.89 ; \mathrm{p}$ value $=0.002$

Table 4. Occupation of women in relation to prevalence of BV.

\begin{tabular}{cccc}
\hline Occupation & No of women with confirmed BV (\%) & No of women negative \& intermediate (\%) & Total no of women studied (\%) \\
\hline Professional & $32(50)$ & $32(50)$ & 64 \\
Skilled & $40(74.1)$ & $14(25.9)$ & 54 \\
Unskilled & $68(73.9)$ & $24(26.1)$ & 92 \\
None & $58(68.2)$ & $27(31.8)$ & 85 \\
& $198(67.7)$ & $97(32.3)$ & $295(100)$ \\
\hline
\end{tabular}

$\mathrm{X}^{2}=11.65 ; \mathrm{p}$ value $=0.008$.

Table 5. Prevalence of BV in relation to coital frequency.

\begin{tabular}{cccc}
\hline Coital freq. per week & No of women with confirmed BV (\%) & No of women negative \& intermediate (\%) & Total no of women studied (\%) \\
\hline$<2$ & $93(60.8)$ & $60(39.2$ & 153 \\
$\geq 2$ & $105(73.9)$ & $37(26.1)$ & 142 \\
& $198(67.7)$ & $97(32.3)$ & $295(100)$ \\
\hline
\end{tabular}

Odds ratio $=0.55 ;$ Relative risk $=0.82 ; \mathrm{X}^{2}=5.78 ; \mathrm{p}$ value $=0.02$.

Table 6. Prevalence of BV in relation to coital frequency.

\begin{tabular}{cccc}
\hline Coital freq. per week & No of women with confirmed BV (\%) & No of women negative \& intermediate (\%) & Total no of women studied (\%) \\
\hline 1 & $93(60.7)$ & $60(39.3)$ & 153 \\
2 & $64(72.0)$ & $25(28.0)$ & 89 \\
3 & $33(82.5)$ & $7(17.5)$ & 40 \\
4 & $4(50)$ & $1(50)$ & 4 \\
5 & $3(75)$ & $0(0)$ & 1 \\
7 & $1(100)$ & $97(32.3)$ & $295(100)$ \\
\hline
\end{tabular}

$X^{2}=9.66 ; p=0.08$ 
nificant $(\mathrm{p}=0.002)$ and may be possibly due to reduction in coital frequency as gestation increases. This finding is in accordance with [22] which showed that the prevalence of $\mathrm{BV}$ was higher at the first trimester of pregnancy.

The high prevalence of BV among pregnant women $(63.7 \%)$ calls for immediate attention to include routine screening of BV of these women and proper and adequate treatment should be administered to prevent its occurrence. Acid gel could be used to maintain the acid $\mathrm{pH}$ of the vagina. Barrier sex such as use of condom or diaphragm should be encouraged to prevent introduction of semen into the vagina during coital contact. There is need for further study of bacterial vaginosis and the factors which influence host susceptibility which may render a woman at risk of the complication associated with $\mathrm{BV}$ in pregnancy such as preterm labour, LBW, miscarriages, higher risk of pelvic inflammatory disease if the bacteria infect the uterus and fallopian tubes. The recognition of such factors and their identification during pregnancy might allow for the treatment of susceptible women in their first as well as subsequent pregnancies and there should be proper follow up.

\section{REFERENCES}

[1] J. Melnick and R. J. Adelberg "Normal Human Microbiota: Normal Microbiotal of the Vagina," McGraw Hill Lange, Boston, 2010.

[2] O. A. Adekunle and O. A. Ladipo, "Reproductive Tract Infections in Nigeria: Challenges for a Fragile Health Infrastructure," In: A. Germain, K. K. Holmes, P. Piot and J. N. Wasserheit, Eds., Reproductive Tract Infections, Plenum Press, New York, 1992, pp. 297-315.

[3] P. Bhalla, C. Rohit, S. Garg, M. Singh, U. Raina and R. Bhalla, "Prevalence of Bacterial Vaginosis among Women in Delhi India," Indian Journal of Medical Research, Vol. 125, 2007, pp. 167-172.

[4] C. A. Spiegel and M. Roberts, "Mobiluncus curtisii subsp. curtisii sp. nov., Mobiluncus curtisii subsp. holmesii subsp. nov., and Mobiluncus mulieris sp. nov. Curved Rods from the Human Vagina," International Journal of Systematic and Evolutionary Microbiology, Vol. 34, No. 2, 1984, pp. 177-184.

[5] E. F. Murta, A. O. Silva, E. A. Silva and S. J. Adad, "Frequency of Infectious Agents for Vaginitis in Non- and Hysterectomized Women," Archives of Gynaecology and Obstetrics, Vol. 273, 2005, pp. 152-156. doi:10.1007/s00404-005-0023-0

[6] G. Reid, D. Charbonneau, J. Erb, B. B. Kochanowski, D. Beuerman and R. Poehner, "Oral Use of Lactobacillus rhamnosus GR-1 and L. fermentum RC-14 Significantly Alters Vaginal Flora: Randomized, Placebo-Controlled Trial in 64 Healthy Women," FEMS Immunology and Medical Microbiology, Vol. 35, 2003, pp. 131-134. doi:10.1016/S0928-8244(02)00465-0

[7] V. de Lima Soares, A. M. de Mesquita, F. G. Cavalcante,
Z. P. Silva, V. Hora and T. Diedrich, "Sexually Transmitted Infections in a Female Population in Rural North-East Brasil: Prevalence, Morbidity and Risk Factors," Tropical Medicine and International Health, Vol. 8, 2003, pp. 595603. doi:10.1046/j.1365-3156.2003.01078.x

[8] K. C. Anukam, E. O. Osazuwa, I. Ahonkhai and G. Reid, "Lactobacillus Vaginal Microbiota of Women Attending a Reproductive Health Care Service in Benin City, Nigeria," Sexually Transmitted Diseases, Vol. 33, No. 1, 2006, pp. 59-62. doi:10.1097/01.olq.0000175367.15559.c4

[9] R. C. Bump and W. J. Buesching, "Bacterial Vaginosis in Virginal and Sexually Active Adolescent Females: Evidence against Exclusive Sexual Transmission," American Journal of Obstetrics and Gynecology, Vol. 158, 1988, pp. 935-939.

[10] Centers for Disease Control and Prevention, "Sexually Transmitted Diseases Treatment Guidelines," Morbidity and Mortality Weekly Report, Vol. 55, No. RR-11, 2006. http://www.cdc.gov/std/treatment/2006/vaginal-discharge .htm

[11] Centers for Disease Control and Prevention, "Bacterial Vaginosis-CDC Fact Sheet," 2007.

http://www.cdc.gov/STD/BV/STDFact-Bacterial Vaginosis.htm

[12] S. Mullick, D. Datson-Jones, M. Beksinska and D. Mabay, "Sexually Transmitted Infections in Pregnancy: Prevalence, Impact on Pregnancy Outcomes and Approach to Treatment in Developing Countries," Sexually Transmitted Infectious, Vol. 81, 2005, pp. 294-302. doi:10.1136/sti.2002.004077

[13] A. C. Senok, H. Verstraelen, M. Temmerman and G. A. Botta, "Probiotics for the Treatment of Bacterial Vaginosis," Cochrane Database Systematic Review No. 4, 2009, Article ID: CD006289.

[14] O. O. Oduyebo, R. I. Anorlu and F. T. Ogunsola, "The Effects of Antimicrobial Therapy on Bacterial Vaginosis in Non-Pregnant Women," Cochrane Database of Systematic Reviews No. 3, 2009, Article ID: CD006055.

[15] R. P. Nugent, M. A. Krohn and S. L. Hillier, "Reliability of Diagnosing Bacterial Vaginosis Is Improved by a Standardized Method of Gram Stain Interpretation," Journal of Clinical Microbiology, Vol. 29, 1991, pp. 297-301.

[16] H. C. Gram, "Method of Distinguishing between Two Major Classes of Bacteria," Friedländer's Journal Fortschritte der Medizin, 1884.

[17] S. L. Hillier, R. P. Nugent, D. A. Eschenbach, M. A. Krohn, R. S. Gibbs and D. H. Martin, "Association between Bacterial Vaginosis and Preterm Delivery of a LowBirth-Weight Infant," New England Journal of Medicine, Vol. 333, 1995, pp. 1342-1737. doi:10.1056/NEJM199512283332604

[18] J. E. Allsworth and J. F. Peipert, "Prevalence of Bacterial Vaginosis," American Journal of Obstetrics and Gynecology, Vol. 109, No. 1, 2007, pp. 114-120. doi:10.1097/01.AOG.0000247627.84791.91

[19] S. Yen, M. A. Shafer, J. Moncada, C. J. Campbell, S. D. Flinn and C. B. Boyer, "Bacterial Vaginosis in Sexually Experienced and Nonsexually Experienced Young Women Entering the Military," Obstetrics and Gynaecology, 
Vol. 102, 2003, pp. 927-933. doi:10.1016/S0029-7844(03)00858-5

[20] R. A. Royce, J. Thorp, J. L. Granados and D. A. Savitz, "Bacterial Vaginosis Associated with HIV Infection in Pregnant Women from North Carolina," Journal of Acquired Immune Deficiency Syndromes and Human Retrovirology, Vol. 20, 1999, pp. 382-386. doi:10.1097/00042560-199904010-00009

[21] T. E. Taha, D. R. Hoover, G. A. Dallabetta, N. J. Kumwenda, L. A. R. Mtimavalye, L. P. Yang, G. N. Liomba, R. L. Broadhead, J. D. Chiphangwi and P. G. Miotti,
"Bacterial Vaginosis and Disturbances of Vaginal Flora: Association with Increased Acquisition of HIV/AIDS," AIDS Official Journal of the International AIDS Society, Vol. 12, No. 13, 1998, pp. 1699-1706. doi:10.1097/00002030-199813000-00019

[22] S. G. Ralph, A. J. Rutherford and J. D. Wilson, "Influence of Bacterial Vaginosis on Conception and Miscarriage in the First Trimester," British Medical Journal, Vol. 319, No. 7204, 1999, p. 220.

doi: $10.1136 / \mathrm{bmj} .319 .7204 .220$ 